\title{
Investigation of Antimicrobial, Antibiofilm, and Cytotoxic Effects of Straight-Chained Sulfanyl Members of Arylamino-1,4-naphthoquinones as Potential Antimicrobial Agents
}

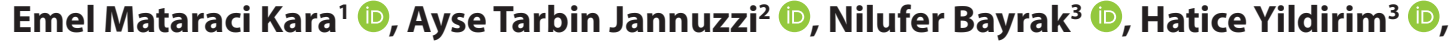 \\ Mahmut Yildiz ${ }^{4}$ (D) Amac Fatih Tuyun ${ }^{5}$ (D), Buket Alpertunga² (D), Berna Ozbek Celik ${ }^{1}$ \\ IIstanbul University, Faculty of Pharmacy, Department of Pharmaceutical Microbiology, Istanbul, Turkey \\ ${ }^{2}$ Istanbul University, Faculty of Pharmacy, Department of Pharmaceutical Toxicology, Istanbul, Turkey \\ ${ }^{3}$ Istanbul University-Cerrahpasa, Engineering Faculty, Chemistry Department, Istanbul, Turkey \\ ${ }^{4}$ Gebze Technical University, Faculty of Science, Department of Chemistry, Kocaeli, Turkey \\ ${ }^{5}$ Istanbul University-Cerrahpasa, Engineering Faculty, Engineering Sciences Department, Istanbul, Turkey
}

ORCID IDs of the authors: E.M.K. 0000-0003-4541-1893; A.T.J. 0000-0003-0578-6893; N.B. 0000-0002-0777-4012; H.Y. 0000-0003-3988-6120; M.Y. 0000-0001-6317-5738; A.F.T. 0000-0001-5698-1109; B.A. 0000-0001-6043-7560; B.O.C. $0000-0001-8909-8398$

Please cite this article as: Mataraci Kara E, Jannuzzi AT, Bayrak N, Yildirim H, Yildiz M, Tuyun AF, Alpertunga B, Ozbek Celik B. Investigation of Antimicrobial, Antibiofilm, and Cytotoxic Effects of Straight-Chained Sulfanyl Members of Arylamino-1,4naphthoquinones As Potential Antimicrobial Agents. Eur J Biol 2019; 78(2): 114-120. DOI: 10.26650/EurJBiol.2019.0017

\begin{abstract}
Objective: Naphthoquinone derivatives are known to have antibacterial activity and are likely to succeed a new class of compound that can be applied as antimicrobial agents.

Materials and Methods: The purpose of this experiment was to evaluate the potential antimicrobial, antibiofilm, anticancer, and cytotoxic activities of six naphthoquinone compounds previously reported in the literature.

Results: According to our studies, 2-(4-(trifluoromethyl)phenylamino)-3-(propylthio)naphthalene-1,4-dione (5a) and 2-(4-(trifluoromethyl)phenylamino)-3-(pentylthio)naphthalene-1,4-dione (5b) were found to have good antimicrobial activity against Staphylococcus aureus ATCC 29213 with 1.22 and $19.53 \mu \mathrm{g} / \mathrm{mL}$ MIC values, respectively. When we carried out the test against biofilm, the most effective agent, $5 \mathrm{a}$, showed up to $40 \%$ inhibition of the $S$. aureus's biofilm at the $1 \times$ MIC concentration. However, when we investigated the cytotoxic effect of $5 a$ on the cancer and non-cancer cell lines, we found that 5 a showed higher toxicity to cancer cell lines.

Conclusion: The findings of our study suggest that further studies to develop these compounds and investigate its pharmacological properties could be useful to define the functionality of them as antimicrobial or anticancer agents.

Keywords: Sulfanyl 1,4-naphthoquinone, Arylamine, Antimicrobial activity, Cytotoxicity, Biofilm
\end{abstract}

\section{INTRODUCTION}

Discovering the potential of naphthoquinone compounds as antimicrobial agents increased the efforts towards synthesis new molecules and investigation of their antimicrobial properties by scientists $(1,2)$. Structure- activity relationship studies performed to determine structural features or functional groups of the naphthoquinone derivatives that increase or decrease antimicrobial activity pointed out that the incorporation of substituted aromatic ring and sulphur (S) atom in the quinone skeleton was an important factor for enhancing 
the biological activities (3). The increase in the number of studies on this subject is not surprising. In this context, it is no surprise that recent studies contain these activity increasing substituents $(4,5)$. Recently Errante et al. reported that some thio derivatives of naphthoquinones exhibited better activities than amphotericine $B$ against some fungi (6). In a previous study, phenylamino derivatives of naphthoquinone that also bear straight chain thiol groups in the structure as substituents were obtained. Infrared, NMR $\left({ }^{1} \mathrm{H},{ }^{13} \mathrm{C}\right)$, and mass spectrometry were first used by Bayrak to identify their structures as original compounds (Figure 1) (7).

In the present study, we evaluated the potential antimicrobial, antibiofilm, and bactericidal efficacies of previously synthesized (7) thio derivatives of phenylamino-naphthoquinones against several pathogen microorganisms. Moreover, the cytotoxic activity of compound $\mathbf{5} \mathbf{a}$ (which has the strongest antimicrobial activity in diverse cancer cell lines in comparison to non-cancerous cell lines) was examined.

\section{MATERIALS AND METHODS}

\section{Microorganisms}

The proposed routine quality control strains used in order to screen test performance with synthesized compounds in test panels are shown in Table 1. Staphylococcus aureus (ATCC 25923) was included in the experiment as a reference strain to confirm the biofilm forming bacteria to ensure antibiofilm activity of the
Table 1. The proposed routine quality control strains used to screen test performance with synthesized compounds in test panels.

\begin{tabular}{lc}
\hline Organisms & Culture Collection Numbers \\
\hline Escherichia coli & ATCC 25922 \\
\hline Staphylococcus aureus & ATCC 29213 \\
\hline Staphylococcus epidermidis & ATCC 12228 \\
\hline Enterococcus faecalis & ATCC 29212 \\
\hline Pseudomonas aeruginosa & ATCC 27853 \\
\hline Proteus mirabilis & ATCC 14153 \\
\hline Klebsiella pneumoniae & ATCC 4352 \\
\hline Candida albicans & ATCC 10231 \\
\hline Candida parapsilosis & ATCC 22019 \\
\hline Candida tropicalis & ATCC 750 \\
\hline ATCC: American Type Culture Collection, 12301, Parklawn Drive, Rockville, MD \\
20852, USA.
\end{tabular}

compound. Inoculums of bacteria and yeasts were prepared with overnight cultures to cultivate a concentration of $1 \times 10^{8}$ colony forming units $(\mathrm{CFU} / \mathrm{mL})$ and $1 \times 10^{7} \mathrm{CFU} / \mathrm{mL}$, respectively.

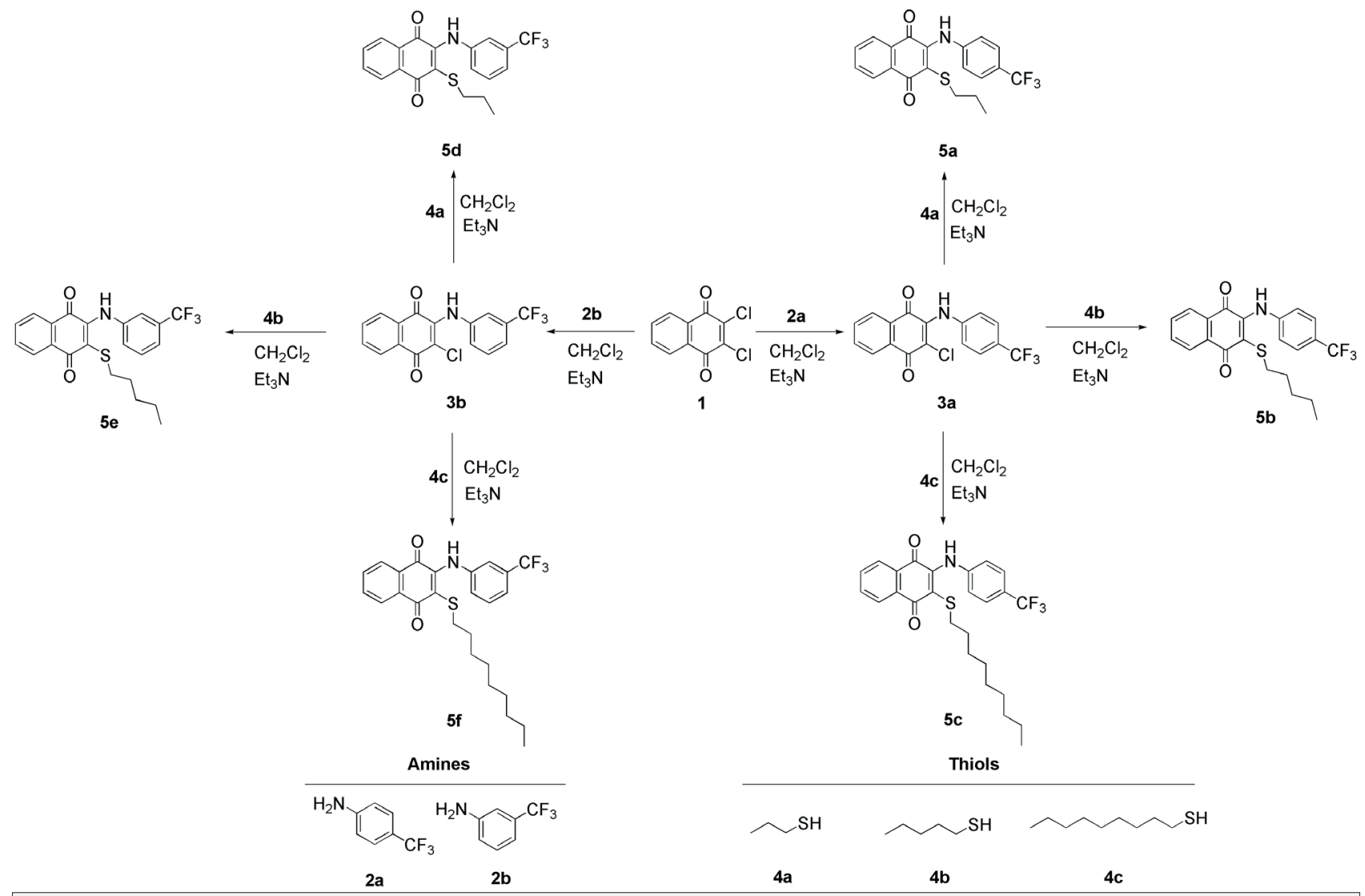

Figure 1. Straight-chained thio phenylamino-1,4-naphthoquinone derivatives. 


\section{Media}

Tryptic soy broth (TSB- Difco Laboratories) plus $1 \%$ glucose was used for the biofilm production and antibiofilm activities assays. Mueller-Hinton broth (MHB, Oxoid) was used to identify the minimum inhibitory concentration (MIC) and time-kill curve; and Tryptic Soy agar (TSA, Difco Laboratories) was used for vital growth colony counts.

\section{Antimicrobial Activity Assessment}

\section{Minimum Inhibitory Concentration Assay}

This assay comprises of the determination of the synthesized compounds'spectrum of antimicrobial susceptibility in compliance with the resistance of studied Gram positive/negative bacteria and yeasts by the CLSI broth microdilution reference method $(8,9)$. The MIC was defined as the lowest concentration of the molecules causing complete inhibition in visible growth. The antimicrobial effect of the solvents was determined as a control and the test results were evaluated accordingly.

The conclusion from the antimicrobial activity tests prompted our research to investigate in vitro antimicrobial activities of compound $\mathbf{5 a}$ contrary to 20 clinically obtained strains of Staphylococcus aureus by the CLSI broth microdilution reference method (8).

\section{Antibiofilm Activity Assesment}

The initial biofilm attachment assay and inhibition of biofilm formation tests were performed by using a slightly modified version of the method by Mataraci et al. (10) that was previously explained. $1 / 10 \times$ MICs of the compound 5 a were appended to the $24 \mathrm{~h}$ biofilm and the plates were incubated for 1, 2 and $4 \mathrm{~h}$ for $S$. aureus ATCC 25923 (biofilm forming bacteria) at $37^{\circ} \mathrm{C}$; molecules at $1 \mathrm{x}, 1 / 10 \mathrm{x}$ and $1 / 100 \mathrm{x}$ MIC concentrations were appended to the $24 \mathrm{~h}$ biofilm and the wells were incubated for $24 \mathrm{~h}$ at $37^{\circ} \mathrm{C}$, respectively. Six wells were used for the tested compound. Sterile TSB-glucose was used for the positive controls. Then the plates were washed with PBS and evaluated at OD595 nm (BioTek EON Microplate Reader).

\section{Determination of Bactericidal Effects by Time-Kill Curves}

Time-kill curve analyses were performed by culturing S. aureus ATCC 29213 in MHB medium, in the presence of $\mathbf{5 a}$ at $1 \times$ MIC. An assessment of the dynamic bactericidal activity of compound $\mathbf{5 a}$ was made with the time-kill curve method by testing at $1 x$ times the MIC against S. aureus ATCC 29213 as described previously. Solvent containing the control was included in the test for the tested strain. The inoculum was quantified spectrophotometrically and added to the flasks. The antimicrobial amount was checked by the inhibition of viable colony growth at the site of the initial inoculum in accordance with NCCLS recommendations (11). Bactericidal activity was described as a decrease of $\geq 3 \log _{10}$ CFU/ $\mathrm{mL}$ from the initial inoculum at $24 \mathrm{~h}$.

\section{Cell Cultures}

Three non-cancer cell lines were used in this study: Mouse embryonic fibroblast (BALB/3T3), human umbilical vein endothelial cell (HUVEC), and human keratinocyte ( $\mathrm{HaCaT})$. The three cancer cell lines used were human hepatocelular carcinoma (HepG2), human neuroblastoma (SH-SY5Y), and human prostate cancer cell (PC-3). All cells were grown with DMEM medium containing $10 \%$ fetal bovine serum and $1 \%$ antibiotic-antimicotic solution in a $37^{\circ} \mathrm{C}, 5 \% \mathrm{CO}_{2}$ humidified incubator. The cells were passaged routinely at a confluence of $90 \%$ by trypsinization.

\section{Cell Treatments and Cytotoxicity Assay}

For the cytotoxicity assay, the cells were seeded in 96 well plates $1 \times 10^{4}$ cells/well and incubated overnight for cell attachment. Subsequently, the media were replaced with fresh media and the cells were treated with compound final concentrations 100-6.25 $\mu \mathrm{g} / \mathrm{mL}$ and vehicle control $1 \%$ DMSO for $24 \mathrm{~h}$ at $37^{\circ} \mathrm{C}$. After 24 hours, cell viability was measured using the 3-(4,5-dimethylthiazol2-yl)-2,5-diphenyltetrazolium bromide (MTT) assay. The final volume of the $5 \mathrm{mg} / \mathrm{mL}$ MTT reagent was added to the wells and the plates were incubated in the dark for $3 \mathrm{~h}$.

The media was then removed and the formazan precipitates were dissolved in $100 \mu \mathrm{L}$ DMSO. Optical density was measured using a microplate reader (Biotek Instruments, Inc., Vermont, USA) at $590 \mathrm{~nm}$. Cell viability was expressed as a percentage of the absorbance recorded for vehicle control.

\section{Statistical Analysis}

All tests were performed in three independent assays. Oneway ANOVA, Bonferroni's multiple comparison test was used to compare the differences between the control and compoundtreated biofilms and time-kill kinetics. A $p$ value $<0.001$ was considered as statistically significant.

\section{RESULTS}

\section{Molecules}

In this study, we used six molecules (2-(4-(trifluoromethyl) phenylamino)-3-(propylthio)naphthalene-1,4-dione (5a), 2-(4-(trifluoromethyl)phenylamino)-3-(pentylthio)naphthalene1,4-dione (5b), 2-(4-(trifluoromethyl)phenylamino)-3-(nonylthio) naphthalene-1,4-dione (5c), 2-(3-(trifluoromethyl)phenylamino)3-(propylthio)naphthalene-1,4-dione (5d), 2-(3-(trifluoromethyl) phenylamino)-3-(pentylthio)naphthalene-1,4-dione (5e), 2-(3-(trifluoromethyl)phenylamino)-3-(nonylthio)naphthalene1,4-dione (5f) ) that had been previously synthesized by Bayrak (7). Bayrak reported that the thiol derivatives of phenylamino1,4-naphthoquinones (5a-f) were obtained by a substitution reaction with phenylamino-chloro-1,4-naphthoquinone derivatives $(\mathbf{3} \mathbf{a}-\mathbf{b})$ that synthesized by the chemical reaction of 2,3-dichloro-1,4-naphtoquinone with trifluoro substituted phenyl amines and the appropriate straight-chained thiol in dichloromethane were mixed at room temperature by applying $\mathrm{Et}_{3} \mathrm{~N}$ (7). The reactions of 2-(4-(trifluoromethyl)phenylamino)3-chloronaphthalene-1,4-dione (3a) and 2-(3-(trifluoromethyl) phenylamino)-3-chloronaphthalene-1,4-dione (3b) with aliphatic thiol compounds (propane, pentane, and nonane thiol) proceeded via the substitution of a chlorine atom with a sulfur atom to form phenylamino-1,4-naphthoquinones with straight chain thio group (5a-f). The structures of $\mathbf{5 a - f}$ were also clarified by IR, ${ }^{1} \mathrm{H} N M R,{ }^{13} \mathrm{C}$ NMR, and MS data (Figure 1). 


\section{Antimicrobial Activity}

The in vitro antimicrobial activity of six thio phenylamino1,4-naphthoquinone derivatives (5a-f) against three Grampositive bacteria, four Gram-negative bacteria, and three fungi by the microbroth dilutions technique using the CLSI recommendations $(8,9)$.

The antimicrobial experiment results of all the six sulfanyl derivatives of phenylamino-1,4-naphthoquinone (5a-f) are given in Table 2. The test-cultures E. coli, P. mirabilis, and K. pneumoniae appeared to be resistant to the all synthesized compounds. None of the studied molecules showed any antibacterial activity against the Gram-negative bacteria except for $\mathbf{5 f}$. Concerning the antibacterial activity, the Gram-positive bacteria were more susceptible to the sulfanyl derivatives of phenylamino-1,4naphthoquinone than the Gram-negative ones. Generally, the findings showed that some compounds displayed varying effects on the growth of the tested Gram-positive bacterial strains. The results showed that all thio-phenylamino-1,4-naphthoquinone derivatives exhibited antimicrobial activity against S. aureus. 5a and $\mathbf{5 b}$ showed good activity against $S$. aureus with an MIC value of 1.22 and $19.53 \mu \mathrm{g} / \mathrm{mL}$, respectively. Notably, 5 a had the same inhibitory activity against $\mathrm{S}$. aureus as that of Cefuroxime-Na $(\mathrm{MIC}=1.22 \mu \mathrm{g} / \mathrm{mL})$. An evaluation of the antifungal activity of the thio- phenylamino-1,4-naphthoquinone derivatives exhibited no antifungal activity against $C$. albicans, C. parapsilosis, and C. tropicalis except $\mathbf{5 d}$. The $\mathbf{5 d}$ was active analog against $C$. tropicalis (MIC $=312.5 \mu \mathrm{g} / \mathrm{mL}$ ) (Table 2). According to our results, 5 a was found active against the standard S. aureus, so we investigated the potential antimicrobial activity of this compound against 20 clinically obtained Staphyloccocus aureus (Table 3). Susceptibility testing demonstrated that the MIC ranges for 5a were 1250->2500 $\mu \mathrm{g} / \mathrm{mL}$, for these clinically obtained strains.

\section{Antibiofilm Activities}

Because of the its potent activity, only 5a was used in the antibiofilm activities assays. When we carried out these tests, the agent inhibited the biofilm attachment according to time, and it showed an important inhibitor activity against biofilm formation at $24 \mathrm{~h}$ depending on concentration (Figure 2).

\section{Time-kill Kinetics}

Time-kill kinetic studies showed that the naphthoquinone compounds used in this study displayed concentration-dependent bactericidal activity. When $\mathbf{5 a}$ a was used at $1 \times$ MIC, bactericidal activity was not seen for the studied strain $S$. aureus ATCC 29213 at 24 h (Figure 3). However, in our study 5a only showed approximately $2 \log _{10}$ reduction in bacterial cell count at the $1 \times$ MIC concentration used.

\section{Cytotoxicity Assay}

The cytotoxicity of 5a was screened in three different noncancer cell lines, mouse embryonic fibroblast (BALB/3T3), human umbilical vein endothelial cell (HUVEC), and human keratinocyte ( $\mathrm{HaCaT})$, together with three cancer cell lines, human hepatocellular carcinoma (HepG2), human neuroblastoma ( $\mathrm{SH}$ SY5Y), and human prostate cancer cell (PC-3). In all cell lines $\mathbf{5 a}$

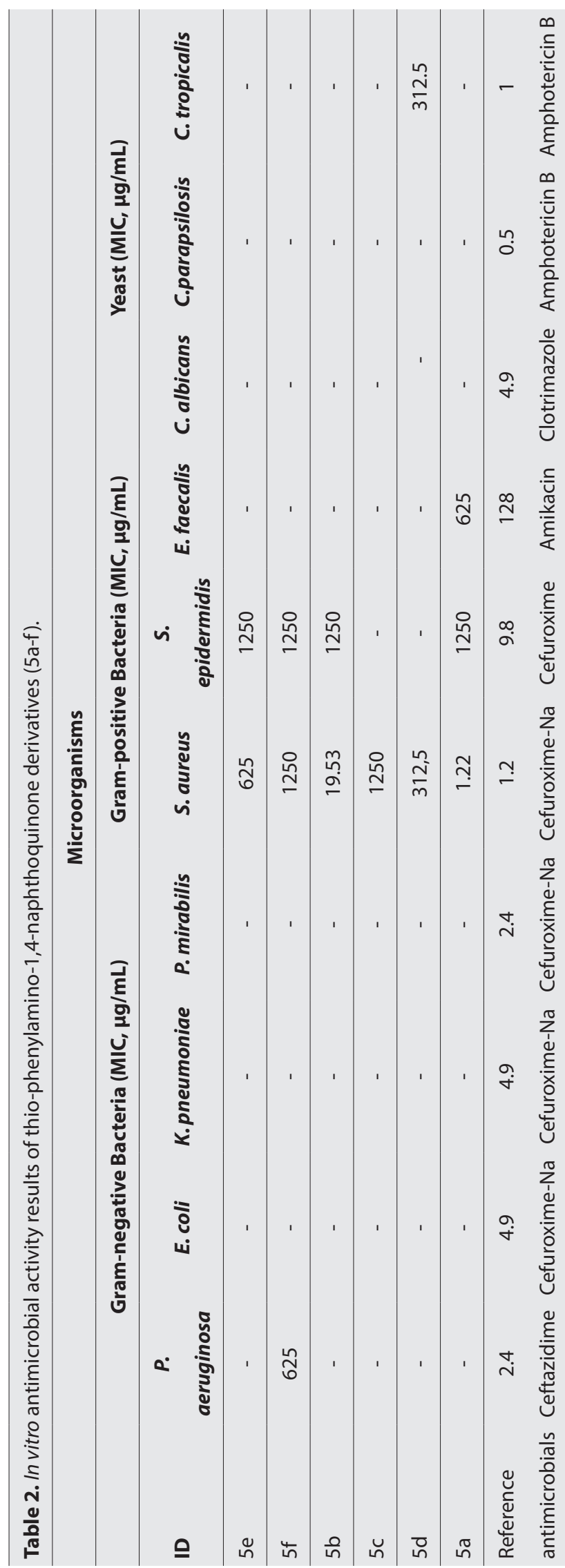


A

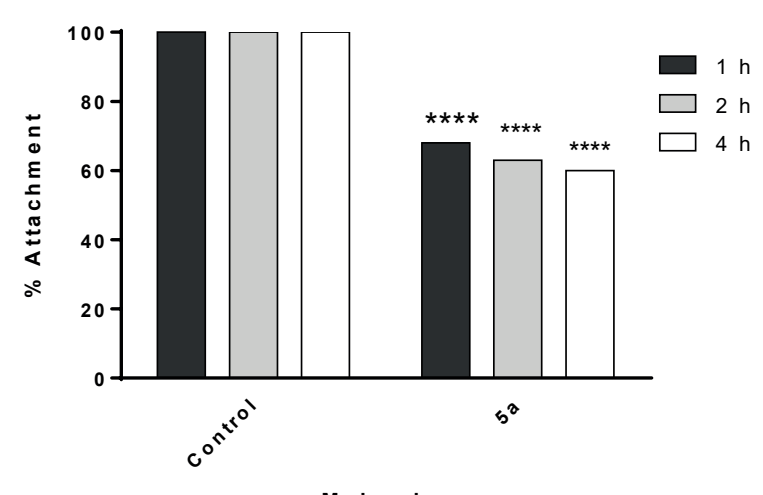

B

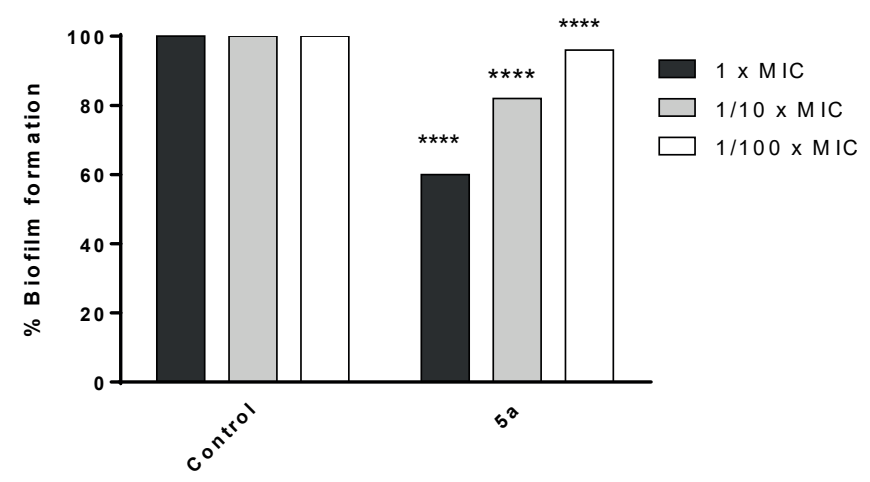

Molecules

Figure 2. Inhibition of S. aureus. A: surface attachment to the wells contained $1 / 10 \times \mathrm{MIC}$ of molecule and an inoculum of $1 \times 10^{7} \mathrm{CFU} / 200$ $\mu \mathrm{l}$, incubated for 1,2 , or $4 \mathrm{~h}$ at $37^{\circ} \mathrm{C}$; B: biofilm formation in each well contained $1 \times, 1 / 10 \times$, or $1 / 100 \times$ MIC of molecule and an inoculum of $5 \times 10^{5} \mathrm{CFU} / 200 \mu \mathrm{l}$, incubated for $24 \mathrm{~h}$ at $37^{\circ} \mathrm{C}$. Control bars indicate bacterium without molecule accepted as $100 \%$. Six wells were used for the tested molecule. Each experiment is representative of three independent tests. All differences between the control and molecule treated biofilms were statistically significant $(p<0.001)$.

decreased cell proliferation significantly after $24 \mathrm{~h}$. The most significant effect was seen in the HepG2 cell line with an $\mathrm{IC}_{50}$ value of $21.96 \mu \mathrm{g} / \mathrm{mL}$. 5a showed a similar cytotoxic effect in the SH-SY5Y and PC-3 cells with $\mathrm{IC}_{50}$ values of $31.94 \mu \mathrm{g} / \mathrm{mL}$ and $31.95 \mu \mathrm{g} / \mathrm{mL}$, respectively (Figure 4). 5 a had IC ${ }_{50}$ values of 60.72 $\mu \mathrm{g} / \mathrm{mL}, 5727 \mu \mathrm{g} / \mathrm{mL}$, and $38.8 \mu \mathrm{g} / \mathrm{mL}$ against non-cancer cells, $\mathrm{HaCaT}, 3 \mathrm{~T} 3$, and HUVEC cells respectively (Figure 5), implies that higher concentrations of compound exhibit toxicity to non-cancer cells.

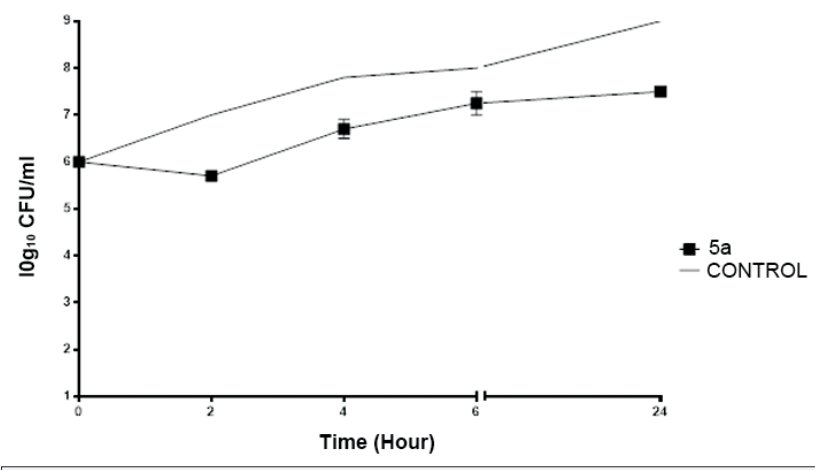

Figure 3. Time kill determinations for S. aureus ATCC 29213 strain after treatment with $5 \mathrm{a}$ alone at $1 \times$ MIC. The $\mathrm{x}$-axis represents the killing time, and the $y$-axis represents the logarithmic $S$. aureus survival.

Table 3. In vitro activities of 5 a against 20 clinically obtained strains of S.aureus.

\begin{tabular}{lccc}
\hline \multirow{2}{*}{ Molecule } & \multicolumn{3}{c}{ Staphylococcus aureus } \\
\cline { 2 - 4 } & MIC range & MIC50 & MIC90 \\
\hline $5 a$ & $1250->2500$ & 1250 & 2500 \\
\hline
\end{tabular}

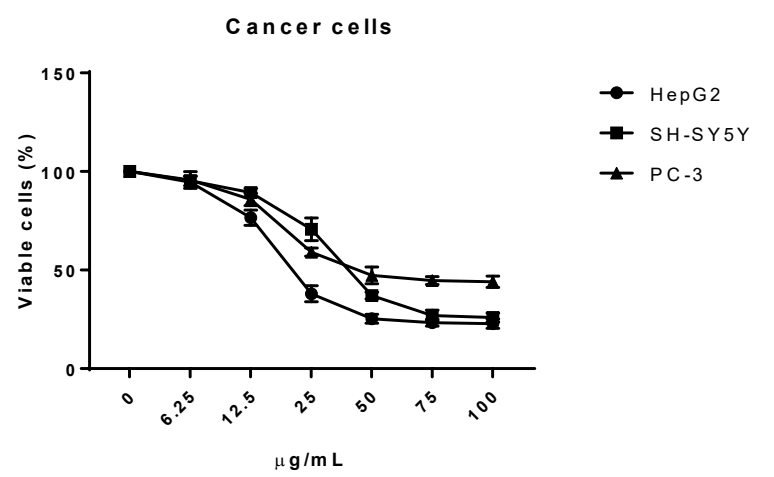

Figure 4. Cytotoxic effect of 5a against HepG2, SH-SY5Y and PC-3 cells determined by MTT assay. Each point representing the mean of three separate biological experiments \pm S.D.

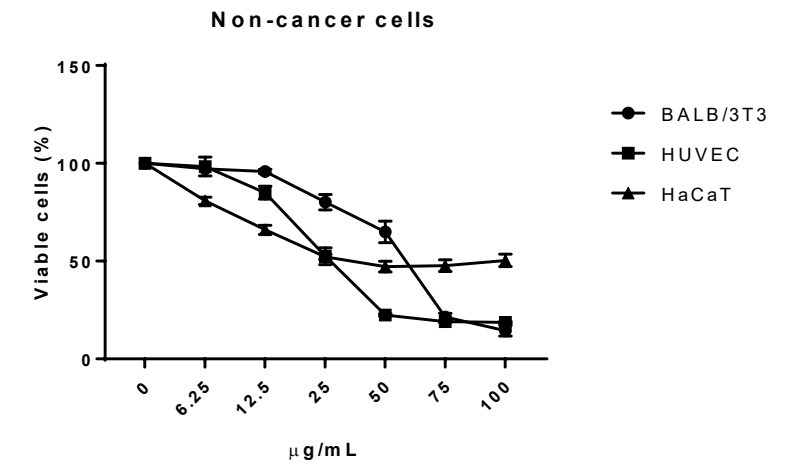

Figure 5. Cytotoxic effect of 5a against BALB/3T3, HUVEC and $\mathrm{HaCaT}$ cells determined by MTT assay. Each point representing the mean of three separate biological experiments \pm S.D. 


\section{DISCUSSION}

The increase and spread of antimicrobial resistance among the various microorganisms is now one of the world's major health problems. Antibiotic resistance is increasing both in the community and in hospitals, multidrug resistant (MDR) and evenpan resistant strains (resistant to all common antibiotic groups for therapeutic use), which lead to failure of antibiotic treatment, increased mortality and morbidity and have a huge increase on the cost of medical treatment and prevention of bacterial infectious diseases $(12,13)$. For these reasons, researchers have produced many synthetic or semi-synthetic molecules as candidates for new and benefical drugs (13-15). The discovery of new antibacterial agents or multidrug agents for reversing is critical as we may not have any effective medicines to treat bacterial infections caused by the emerging superbugs that are resistant to the majority of clinically available antibiotics (16).

In our present study, the in vitro actimicrobial activities of known phenylamino derivatives of naphthoquinone having straight chain thiol groups were evaluated and two molecules (5a and $\mathbf{5} \mathbf{b}$ ) were found to have a potent antibacterial efficacy against S.aureus human-pathogenic strains and causes not only community acquired but also immortal nosocomial infections (10).

The communities of microorganisms attached to a surface were termed 'biofilm'. Bacteria within the biofilm require a 100 to 1000 times greater antibiotic concentration to achieve destruction versus planktonic bacteria. Standard intravenous therapy does not reach a high enough concentration to reduce the bacterial burden within the biofilm. It is a fact that this is the case for up to $60 \%$ of the infections which are usually associated with microorganisms that have settled in the microbial biofilms. Not all antimicrobial agents are the same in terms of biofilm eradication. The agent's mechanism of action, its interaction with the biofilm matrix and the effect of biofilm related parameters such as oxygen concentration, biofilm and growth rate should be considered (17-19). To this end, we researched the inhibition of surface bacterial adhesion and the inhibition of biofilm production by MIC or sub-MIC values of the 5a compound. 5a significantly inhibited the attachment of bacteria at 1/10 x MIC in 1-4 h and $24 \mathrm{~h}$ biofilm formation up to $40 \%$, in particular at $1 \times$ MIC $(p<0.001)$. Although the inhibition of mature biofilm is very difficult, the inhibition of biofilm formation seems to be more applicable in early critical stages.

Although $\mathbf{5 a}$ has limited bactericidal activity against $S$. aureus at $1 \times \mathrm{MIC}$, it could be considered for future studies since its combination with antibiotics as an adjuvant could cause synergism, thus lowering 5a's potential toxic effects and preventing the development of resistance. Moreover, comparing the cytotoxic effect of the compound on non-cancer and cancer cell lines, we noticed that 5 a showed higher toxicity to cancer cell lines. Human hepatocellular cancer HepG2 cells in particular were the most effected cells. This result may suggest potential anticancer use against human hepatocellular cancer.

$\mathrm{HaCaT}$ cells are immortalized human keratinocytes and it is a useful model for studying dermal toxicity. 5a showed the least toxicity to the $\mathrm{HaCaT}$ cells and $\mathrm{IC}_{50}$ value was over $60 \mu \mathrm{g} / \mathrm{mL}$. Also, increasing doses of the compound did not cause more cytotoxic effect in the $\mathrm{HaCaT}$ cells. Additionally, the compound showed a 2-fold higher $\mathrm{IC}_{50}$ value to the mouse embryonic fibroblast BALB/3T3 cells than the cancer cells. These results may indicate potential antibacterial dermal use of the compound in low concentrations without causing significant dermal toxicity. Follow-up research is essential to understand the compound's mechanism of action and define detailed the activity-structure relationship.

\section{CONCLUSION}

With respect to the antimicrobial, anticancer, and cytotoxic activities of the phenylamino derivatives of naphthoquinone that contain straight chain thiol groups in the structure as substituents which had been previously synthesized, further studies to establish their pharmacological properties would be helpful to define their functionality as antimicrobial or anticancer agents.

Peer-review: Externally peer-reviewed.

Author Contributions: Conception/Design of study: E.M.K., A.T.J., N.B., B.O.C., B.A., M.Y., A.F.T., H.Y.; Data Acquisition: E.M.K., A.T.J., N.B., B.O.C., B.A., H.Y.; Data Analysis/Interpretation: E.M.K., A.T.J., N.B., B.O.C., B.A., M.Y., A.F.T., H.Y.; Drafting Manuscript: B.O.C., B.A., M.Y., B.O.C., B.A., M.Y.; Critical Revision of Manuscript: E.M.K., A.T.J., N.B., B.O.C., B.A., M.Y., A.F.T., H.Y.; Final Approval and Accountability: E.M.K., A.T.J., N.B., B.O.C., B.A., M.Y., A.F.T., H.Y.; Technical or Material Support: E.M.K., A.T.J., N.B., B.O.C., B.A., M.Y., A.F.T., H.Y.; Supervision: E.M.K., A.T.J., N.B., B.O.C., B.A., M.Y., A.F.T., H.Y.

Conflict of Interest: The authors declare that they have no conflicts of interest.

Financial Disclosure: There are no funders to report for this submission.

\section{REFERENCES}

1. Ryu CK, Shim JY, Chae MJ, Choi IH, Han JY, Jung OJ, et al. Synthesis and antifungal activity of 2/3-arylthio- and 2,3-bis(arylthio)-5hydroxy-/5-methoxy-1,4-naphthoquinones. Eur J Med Chem 2005; 40 (5): 438-44.

2. Bayrak N, Yıldırım H, Tuyun AF, Mataracı-Kara E, Ozbek-Celik B, Gupta GK, et al. Synthesis, computational study, and evaluation of in vitro antimicrobial, antibiofilm, and anticancer activities of new sulfanyl aminonaphthoquinone derivatives. Lett Drug Des Discov 2016; 13 (999).

3. Ryu CK, Lee JY, Jeong $\mathrm{SH}$, Nho JH. Synthesis and antifungal activity of $1 \mathrm{H}$-pyrrolo[3,2-g]quinoline-4,9-diones and 4,9-dioxo4,9-dihydro-1H-benzo[f]indoles. Bioorg Med Chem Lett 2009; 19: 146-8.

4. Yıldırım H, Bayrak N, Tuyun AF, Mataracı-Kara E, Ozbek-Celik, B, Gupta GK. 2,3-disubstituted-1,4-naphthoquinones containing an arylamine with trifluoromethyl group: synthesis, biological evaluation, and computational study. Rsc Adv 2017; 7: 25753-64.

5. Kacmaz A, Acar ET, Atun G, Kaya K, Sigirci BD, Bagcigil F. Synthesis, electrochemistry, DFT calculations, antimicrobial properties and X-ray crystal structures of some $\mathrm{NH}$ - and/or S- substituted-1,4quinones. Chemistryselect 2018; 3: 8615-23. 
6. Errante G, Motta GL, Lagana C, Wittebolle V, Sarciron MÉ, Barret R. Synthesis and evaluation of antifungal activity of naphthoquinone derivatives. Eur J Med Chem 2006; 41: 773-8.

7. Bayrak N. Novel straight-chained sulfanyl members of arylamino1,4-naphthoquinones: synthesis and characterization. JOTCSA 2017; 4(2): 597-606.

8. Clinical and Laboratory Standards Institute (CLSI), Methods for dilution antimicrobial susceptibility tests for bacteria that grow aerobically, in, Wayne, PA, USA, 2006.

9. Clinical and Laboratory Standards Institute (CLSI), Reference Method for Broth Dilution Antifungal Susceptibility Testing of Yeasts; Approved Standard-Second Edition, in, Wayne, PA, USA, 1997.

10. Mataracı E, Döşler $S$. In vitro activities of antibiotics and antimicrobial cationic peptides alone and in combination against methicillin resistant Staphylococcus aureus biofilms. Antimicrob Agents Chemother 2012; 56: 6366-71.

11. National Committee for Clinical Laboratory Standards. Methods for Determining Bactericidal Activity of Antimicrobial AgentsApproved Guideline M26 A. Wayne NCCLS, 1999.

12. Cepas V, López $Y$, Muñoz E, Rolo D, Ardanuy C, Martí S, et al. Relationship between biofilm formation and antimicrobial resistance in gram-negative bacteria. Microb Drug Resist 2019; 25(1): 72-9.
13. Döşler $S$, Mataracı-Kara E, Başpinar Küçük H, Yusufoğlu AS. Antibacterial and anti-biofilm activities of new chiral and racemic 1,3-dioxolanes. Istanbul J Pharm 2015; 45(1): 19-28.

14. Calderone R, Sun N, Gay-Andrieu F, Groutas W, Weerawarna P, Prasad S, et al. Antifungal drug discovery: the process and outcomes. Future Microbiol 2014; 9: 791-805.

15. Nigam A, Gupta D, Sharma A. Treatment of infectious disease: Beyond antibiotics. Microbiol Res 2014; 169: 643-51.

16. Mosolygó T, Kincses A, Csonka A, Tönki ÁS, Witek K, Sanmartín C, et al. Selenocompounds as novel antibacterial agents and bacterial efflux pump inhibitors. Molecules 2019; 24: 1487.

17. Jamal M, Ahmad W, Andleeb S, Jalil F, Imran M, Nawaz MA, et al. Bacterial biofilm and associated infections. J Chin Med Assoc 2018; 81(1): 7-11.

18. Donlan RM, Costerton JW. Biofilms: survival mechanisms of clinically relevant microorganisms. Clin Microbiol Rev 2002; 15 : 167-93.

19. Hoiby N, Bjarnsholt T, Moser C, Bassi GL, Coenye T, Donelli G, et al. ESCMID guideline for the diagnosis and treatment of biofilm infections 2014. Clin Microbiol Infect 2015; 21(S1): S1-S25. 